\title{
Long-term effects of bosentan in patients with HIV-associated pulmonary arterial
} hypertension

\author{
B. Degano*,\#, A. Yaïci*, J. Le Pavec*, L. Savale*, X. Jaïs*, B. Camara\#, M. Humbert*, \\ G. Simonneau* and O. Sitbon*
}

ABSTRACT: Bosentan has proven 4-month efficacy in patients with HIV-associated pulmonary arterial hypertension (PAH-HIV). Herein, the long-term outcome of unselected PAH-HIV patients treated with first-line bosentan is described.

Data for 59 consecutive World Health Organization (WHO) functional class II-IV PAH-HIV patients treated with first-line bosentan between May 2002 and July 2007 were analysed. HIV status, 6-min walk distance and haemodynamics were assessed at baseline, after 4 months and every 6-12 months thereafter.

After 4 months, 6-min walk distance increased from $358 \pm 98$ to $435 \pm 89 \mathrm{~m}$ and pulmonary vascular resistance decreased from $737 \pm 328$ to $476 \pm 302 \mathrm{dyn} \cdot \mathrm{s} \cdot \mathrm{cm}^{-5}$. At the final evaluation (29 \pm 15 months), 6-min walk distance remained stable and pulmonary vascular resistance decreased further to $444 \pm 356 \mathrm{dyn} \cdot \mathrm{s} \cdot \mathrm{cm}^{-5}$. Haemodynamics normalised in 10 patients. At their last evaluation, these 10 patients were in WHO functional class I, with a 6-min walk distance of $532 \pm 52 \mathrm{~m}$. Overall survival estimates were 93,86 and $66 \%$ at 1,2 and 3 yrs, respectively. Bosentan was safe when combined with highly active antiretroviral therapy, with no negative impact on HIV infection control.

The present data confirm the long-term benefits of bosentan therapy in HIV-associated pulmonary arterial hypertension patients with improvements in symptoms, 6-min walk distance and haemodynamics, and with favourable overall survival.

KEYWORDS: Bosentan, endothelin, HIV, hypertension, pulmonary

\section{P}

ulmonary arterial hypertension $(\mathrm{PAH})$ is a life-threatening complication of HIV infection [1]. The prevalence of PAH in HIVinfected individuals, which is estimated to be $0.5 \%$, is at least 1,000 -fold higher than the prevalence of idiopathic PAH (IPAH) in the general population and does not appear to have changed over recent decades [2]. HIV-infected patients represented $8.1 \%$ of $\mathrm{PAH}$ patients in the 2003-2004 French Registry [3]. The mechanisms underlying the link between HIV infection and PAH have not yet been established. HIV infection increases the risk of development of $\mathrm{PAH}$ regardless of the routes of infection, the stage of HIV infection and the degree of immunodeficiency [4, 5]. Evidence suggests that the presence of PAH has a significant influence on mortality and, in most cases, death is causally related to PAH rather than to other complications of HIV infection $[5,6]$.

The latest treatment guidelines stress that adequate evidence to support the optimal management of
PAH associated with HIV (PAH-HIV) is lacking [7]. There are still conflicting data on the impact of highly active antiretroviral therapy (HAART), with some reports suggesting that HAART has no effect on the presence or severity of PAH [8], and others reporting that HAART reduces mortality associated with PAH-HIV [9]. In the absence of specific recommendations, PAH-HIV treatment follows IPAH treatment guidelines [7]. Acute pulmonary vasodilator response is rare in patients with $\mathrm{PAH}-$ HIV and therefore long-term calcium channel blocker treatment is likely to be inadequate in such patients $[3,10]$. Three classes of drugs are currently approved as "specific therapy" to treat patients with PAH: 1) prostacyclin analogues administered via i.v. (epoprostenol) or subcutaneous (treprostinil) routes, or by inhalation (iloprost); 2) the oral dual endothelin receptor antagonist bosentan; and 3) the phosphodiesterase type 5 inhibitor (PDE5i) sildenafil. The results of small studies suggest that treatment with continuous i.v. infusion of epoprostenol $[5,11]$ and inhaled iloprost [12] may provide

\section{AFFILIATIONS}

*Dept of Respiratory and Intensive Care Medicine, Université Paris-Sud 11, National Reference Centre for Pulmonary Arterial Hypertension, Institut Paris-Sud Cytokines, Hôpital Antoine Béclère, Clamart, and

\#Dept of Respiratory and Intensive Care Medicine, Centre Hospitalier Universitaire Larrey, Toulouse, France.

\section{CORRESPONDENCE}

0 . Sitbon

Service de Pneumologie

Hôpital Antoine Béclère

157 rue de la Porte de Trivaux

92141 Clamart

France

Fax: 33146303824

E-mail: olivier.sitbon@abc.aphp.fr

Received:

June 232008

Accepted after revision:

August 252008

SUPPORT STATEMENT

This study was supported in part by an educational grant from Actelion Pharmaceuticals France. Editorial support was provided by Elements Communications Ltd on behalf of Actelion Pharmaceuticals France.

STATEMENT OF INTEREST Statements of interest for M. Humbert, G. Simonneau and 0 . Sitbon and for the manuscript itself can be found at www.erj.ersjournals.com/misc/ statements.shtml 
benefits for patients with PAH-HIV. However, there are concerns about the long-term use of these drugs [5], especially epoprostenol, which needs a permanent central venous access with the associated potential for infectious complications, particularly in immunocompromised patients. Some studies have reported the efficacy of sildenafil in patients with PAH-HIV [13, 14]; however, drug-drug interactions with protease inhibitors may limit the use of sildenafil in these patients [15]. The selective oral endothelin receptor antagonist ambrisentan appears to have short-term benefits in patients with PAH [16]; however, data from patients with PAH-HIV are as yet either lacking or unpublished. Finally, an open "proof of concept" 4-month study involving 16 patients with PAH-HIV suggested that bosentan improves exercise capacity, quality of life and haemodynamics, without a negative impact on the control of HIV infection [17].

Because of the short-term beneficial results observed with bosentan in patients with PAH-HIV [17], the present authors aimed to investigate the potential benefit and safety of longterm treatment in a larger group of patients treated with firstline bosentan.

\section{MATERIALS AND METHODS Study subjects}

A total 59 consecutive patients with PAH-HIV treated with firstline bosentan between May 2002 and July 2007 at the Antoine Béclère Hospital (Clamart, France) and the Rangueil-Larrey Hospital (Toulouse, France) were evaluated. Out of these patients, 12 had been previously described in a 16-week pilot study conducted in 16 patients to evaluate first-line therapy with bosentan in PAH-HIV [17]; four out of the 16 patients in the earlier study were from centres other than Antoine Béclère Hospital and were therefore not included in the present report. All patients had HIV infection and symptomatic PAH in World Health Organization (WHO) functional class (FC) II-IV. PAH was diagnosed by means of right heart catheterisation (RHC) showing a mean pulmonary arterial pressure $\left(\bar{P}_{\text {pa }}\right)$ at rest of $>25 \mathrm{mmHg}$, a pulmonary capillary wedge pressure $<15 \mathrm{mmHg}$ and a pulmonary vascular resistance (PVR) of $>250 \mathrm{dyn} \cdot \mathrm{s} \cdot \mathrm{cm}^{-5}$. Acute vasodilator testing with inhaled nitric oxide $(10 \mathrm{ppm})$ was performed in all patients, as previously described [18]. Primary lung disease and post-embolic pulmonary hypertension were ruled out by pulmonary function tests, computed tomography and ventilation/perfusion lung scan.

According to French legislation, ethics committee agreement and provision of informed consent are not required for retrospective collection of data corresponding to current practice. The database was, however, compiled anonymously within the restrictive requirements of the Commission Nationale Informatique et Liberté, the organisation dedicated to privacy, information technology and civil rights in France. The present study was approved by the local institutional review board.

\section{Study design}

The goal of the present retrospective study was to describe the long-term outcome of unselected patients with PAH-HIV treated with first-line bosentan.

\section{Methods}

All patients received nonspecific supportive therapies in accordance with current guidelines, including oral anticoagulants to maintain an international normalised ratio of 1.5-2.5 unless contraindicated, diuretics to control signs and symptoms of right heart failure including peripheral oedema, and long-term oxygen therapy if hypoxaemia was present [19]. Patients received a regimen of HAART, if required, according to the most recent recommendations [20]. Bosentan was prescribed at $62.5 \mathrm{mg}$ b.i.d. for 4 weeks, followed by $125 \mathrm{mg}$ b.i.d. thereafter. Liver function tests were performed every 2 weeks during the first 6 weeks and monthly thereafter. In the case of elevated liver enzymes, bosentan was stopped or the dosage was reduced in accordance with current recommendations [21].

All patients underwent a complete baseline evaluation before starting bosentan therapy, including assessment of modified WHO FC, physical examination, routine blood tests and nonencouraged 6-min walk test (6MWT) according to the American Thoracic Society recommendations [22]. WHO FC assessment, non-encouraged 6MWT and RHC were reassessed after 4 and 12 months of bosentan therapy. Noninvasive assessments were repeated every 4-6 months thereafter and RHC once a year.

At the author's centres, an additional specific therapy was indicated when the patient was in WHO FC IV on treatment or persisted in WHO FC III after $\geqslant 4$ months of treatment together with: 1) a 6-min walk distance (6MWD) $<250 \mathrm{~m} ; 2$ ) a decrease in $6 \mathrm{MWD}>10 \%$ from the previous value in two tests performed $\geqslant 2$ weeks apart; or 3 ) a cardiac index (CI) $<2.2 \mathrm{~L} \cdot \mathrm{min}^{-1} \cdot \mathrm{m}^{-2}$ [23]. Some patients in WHO FC IV received bosentan monotherapy because they refused i.v. epoprostenol.

\section{Analysis}

Results were expressed as mean $\pm \mathrm{SD}$ or as median (range). Baseline and post-baseline values for 6MWD, haemodynamic parameters and HIV status were compared using a two-sided paired t-test. Only patients having received bosentan monotherapy for $\geqslant 1$ yr were considered for the last evaluation analysis. For the subgroup of patients in which baseline data, data after 4 months and data at last evaluation were available, comparisons were made using repeated-measures ANOVA. Changes in WHO FC were compared using the Chi-squared test. A p-value $<0.05$ was considered statistically significant.

Analyses of overall survival and event-free status were performed using an intention-to-treat approach. The date of initiation of bosentan therapy was the starting point for determining the follow-up duration and estimating survival. Event-free status was defined as survival without lung transplantation, need of prostacyclin analogues and/or PDE5i therapy, discontinuation of bosentan, or acute right heart failure requiring hospitalisation for i.v. diuretics and/or dobutamine infusion. Patients lost to follow-up were censored as of the date of the last bosentan prescription. The Kaplan-Meier method was used to estimate overall survival and event-free status at each time-point. For patients with more than one event, only the first event was used in the Kaplan-Meier analysis.

Univariate analysis based on the proportional hazards model was used to examine the effect on survival of selected demographic parameters, medical history, portal hypertension, HIV status and haemodynamic variables assessed at baseline. For continuous variables, patients were separated into two groups on both sides of the median value. Results were expressed as hazard ratios with $95 \%$ confidence intervals. 


\section{RESULTS}

\section{Baseline patient characteristics}

Baseline demographics, HIV status and haemodynamics of the 59 patients are described in table 1 . A total of $19(32 \%)$ patients had HIV acquired from i.v. drug use, 20 (34\%) via heterosexual contact, $16(27 \%)$ via homosexual contact, and five $(7 \%)$ via other causes. At the time of PAH diagnosis, the majority of patients $(83 \%)$ were receiving HAART, comprising at least three antiretroviral medications, including protease inhibitors and/or non-nucleoside reverse transcriptase inhibitors or both. Co-infection with hepatitis C $(n=24)$ or B $(n=6)$ virus was present in 30 patients. Of these patients, 10 had mild cirrhosis (Child-Pugh A class). Baseline clinical characteristics and haemodynamics did not differ between patients with and without chronic viral hepatitis, or between patients with and without cirrhosis.

\section{Exercise capacity and haemodynamics after 4 months of bosentan}

Out of 59 patients, 56 were evaluated after 4 months of bosentan monotherapy (table 2). The remaining three patients either died $(n=2)$, or had bosentan stopped because of an

\begin{tabular}{|c|c|c|}
\hline TABLE 1 & \multicolumn{2}{|c|}{$\begin{array}{l}\text { Clinical characteristics of the study population at } \\
\text { baseline }\end{array}$} \\
\hline Patients n & & 59 \\
\hline \multicolumn{3}{|c|}{ Demographics } \\
\hline Male/femal & & $37(63) / 22(37)$ \\
\hline Age yrs & & $40 \pm 15$ \\
\hline Weight kg & & $63 \pm 16$ \\
\hline Caucasian/ & lack & $50(85) / 9(15)$ \\
\hline WHO FC I/ & III/IV n & $0 / 4 / 49 / 6$ \\
\hline 6-min walk & istance m & $355 \pm 99$ \\
\hline \multicolumn{3}{|l|}{ HIV status } \\
\hline \multicolumn{3}{|l|}{ CDC stage } \\
\hline Asympto & atic - A \% & 30 \\
\hline Sympton & tic non-AIDS - B \% & 9 \\
\hline Sympton & tic AIDS - C \% & 61 \\
\hline $\mathrm{CD} 4^{+}$lymp & cyte count cells $\cdot \mathrm{mm}^{-3}$ & $437 \pm 574$ \\
\hline $\mathrm{CD} 4^{+}$lymp & cyte count $>200$ cells $\cdot \mathrm{mm}^{-3}$ & $47(80)$ \\
\hline Undetectak & viral load & $30(51)$ \\
\hline HAART & & $49(83)$ \\
\hline \multicolumn{3}{|c|}{ Haemodynamics } \\
\hline $\bar{P}_{\text {ra }} \mathrm{mmHg}$ & & $8 \pm 5$ \\
\hline $\bar{P}$ pa $\mathrm{mmHg}$ & & $49 \pm 10$ \\
\hline PिPCW mml & & $6 \pm 2$ \\
\hline Cardiac inc & $x \mathrm{~L} \cdot \mathrm{min}^{-1} \cdot \mathrm{m}^{-2}$ & $2.9 \pm 0.7$ \\
\hline PVR dyn.s. & & $749 \pm 321$ \\
\hline $\mathrm{Sv}, \mathrm{O}_{2} \%$ & & $60 \pm 9$ \\
\hline Acute resp & der to inhaled nitric oxide ${ }^{\#} \mathrm{n}$ & 0 \\
\hline
\end{tabular}

Values are expressed as $\mathrm{n}(\%)$ or mean $\pm \mathrm{SD}$, unless otherwise stated. WHO: World Health Organization; FC: functional class; CDC: Centers for Disease Control and Prevention; HAART: highly active antiretroviral therapy; $\bar{P}_{\text {ra: }}$ mean right atrial pressure; $\bar{P}$ pa: mean pulmonary artery pressure; $\bar{P}$ PCW: mean pulmonary capillary wedge pressure; PVR: pulmonary vascular resistance; $\mathrm{Sv}_{1} \mathrm{O}_{2}$ : mixed venous oxygen saturation. ${ }^{\#}$ : an acute response to inhaled nitric oxide was defined as a fall in $\bar{P}_{\mathrm{pa}}$ of $>10 \mathrm{mmHg}$ to reach a value $<40 \mathrm{mmHg}$ with a normal or elevated cardiac output $[7,18]$ increase of liver enzymes $(n=1)$. Among these 56 patients, WHO FC improved in 45 and remained stable in 11 . The $6 \mathrm{MWD}$ increased by a mean of $74 \pm 88 \mathrm{~m}$ (table 2 ), improving in 47 out of 56 patients. Pulmonary haemodynamics significantly improved, with a $19 \%$ increase in $\mathrm{CI}$, an $18 \%$ decrease in $\bar{P}_{\text {pa }}$ and a $35 \%$ decrease in PVR.

\section{Exercise capacity and haemodynamics at last evaluation}

Out of the 56 patients who were evaluated at 4 months, 38 were re-evaluated after $29 \pm 15$ months (range 12-67 months) on bosentan monotherapy (table 2). The remaining 18 patients did not undergo long-term evaluation for the following reasons: 11 were receiving bosentan monotherapy but had not been treated for $\geqslant 1 \mathrm{yr}$ at cut-off, four died after 4 12 months (all were taking bosentan monotherapy) and one received sildenafil in addition to bosentan. Bosentan was stopped in two additional patients because of an increase of liver enzymes. Of these remaining 38 patients on bosentan monotherapy for $\geqslant 1 \mathrm{yr}$, WHO FC improved in 29 patients and remained stable in nine patients at last evaluation compared with baseline. Compared with the 4-month evaluation, 6MWD and CI remained stable, and there was a further decrease in $\bar{P}_{\text {pa }}$ and PVR (table 2).

Notably, haemodynamics were normalised in 10 out of the 59 patients who received first-line bosentan monotherapy. Individual data for these 10 patients are shown in table 3. At the time of last evaluation ( $32 \pm 22$ months), all 10 patients were in WHO FC I, with a significant improvement in 6MWD and normalisation of haemodynamic parameters. At the start of bosentan therapy, three of these patients were in WHO FC II, five were in FC III and two were in FC IV. The baseline haemodynamic parameters, viral load and $\mathrm{CD} 4^{+}$lymphocyte count of these 10 patients were not different from the baseline values of the 28 remaining patients for whom haemodynamics were not normalised on long-term bosentan monotherapy. In the subgroup of 10 patients for whom haemodynamics were normalised, viral load did not significantly decrease at last evaluation compared with baseline values, while $\mathrm{CD} 4^{+}$lymphocyte count significantly increased in the meantime (table 3 ). Conversely, in the subgroup of 28 patients for whom haemodynamics were not normalised, viral load significantly decreased from $2.0 \pm 2.5$ to $1.3 \pm 1.6 \log _{10} \cdot \mathrm{mm}^{-3}(\mathrm{p}=0.02)$ and CD4 ${ }^{+}$lymphocyte count increased from $409 \pm 358$ to $467 \pm 360$ cells $\cdot \mathrm{mm}^{-3}$; however, the difference was not significant $(p=0.32)$. Before starting bosentan, eight patients received HAART and nine had a $\mathrm{CD}^{+}$lymphocyte count of $>200$ cells $\cdot \mathrm{mm}^{-3}$. At the time of last evaluation, all patients were on HAART with a CD4 $4^{+}$lymphocyte count $>200$ cells $\cdot \mathrm{mm}^{-3}$. The number of patients with undetectable viral load remained stable during the follow-up (eight out of 10 at baseline versus seven out of 10 at last evaluation). In one patient, bosentan was permanently interrupted due to reversal of PAH after 2 yrs of treatment. A 6-month follow-up of this patient showed that normalised haemodynamics and WHO FC I were preserved off-treatment.

\section{Evolution of HIV status}

At baseline, 49 (83\%) out of 59 patients were receiving HAART at the time of PAH diagnosis. At this time, $51 \%$ had undetectable viral load and $80 \%$ had a CD4 ${ }^{+}$count $>200$ cells $\cdot \mathrm{mm}^{-3}$ (table 1 ). After 4 months of bosentan monotherapy, 47 (84\%) out of 56 
TABLE 2 Exercise capacity, haemodynamics and HIV status on bosentan monotherapy

\begin{tabular}{|c|c|c|c|c|c|}
\hline & \multicolumn{2}{|c|}{ Patients evaluated more than once } & \multicolumn{3}{|c|}{ Patients evaluated at least three times } \\
\hline & Baseline & 4 months & Baseline & 4 months & Last evaluation $\#$ \\
\hline Patients $\mathbf{n}$ & & & & 38 & \\
\hline WHO FC I/II/III/IV n & $0 / 4 / 45 / 7$ & $9 / 36 / 11 / 0$ & 0/2/34/2 & $6 / 25 / 7 / 0$ & $11 / 18 / 9 / 0$ \\
\hline 6-min walk distance $\mathrm{m}$ & $358 \pm 98$ & $435 \pm 89^{\circ}$ & $357 \pm 80$ & $424 \pm 82^{\circ}$ & $449 \pm 91$ \\
\hline $\bar{P} \mathbf{r a ~ m m H g}$ & $8 \pm 5$ & $5 \pm 3^{\circ}$ & $9 \pm 5$ & $6 \pm 3^{\circ}$ & $6 \pm 4^{\circ}$ \\
\hline $\bar{P}$ pa $\mathbf{m m H g}$ & $49 \pm 10$ & $40 \pm 3^{\circ}$ & $50 \pm 10$ & $40 \pm 13^{\circ}$ & $37 \pm 15^{\circ+}$ \\
\hline Cardiac index $\mathrm{L} \cdot \mathrm{min}^{-1} \cdot \mathrm{m}^{-2}$ & $2.9 \pm 0.7$ & $3.5 \pm 0.8^{\circ}$ & $2.8 \pm 0.6$ & $3.5 \pm 0.7^{\circ}$ & $3.6 \pm 0.9^{\circ}$ \\
\hline PVR dyn $\cdot \mathbf{s} \cdot \mathrm{cm}^{-5}$ & $737 \pm 328$ & $476 \pm 302^{\circ}$ & $769 \pm 355$ & $470 \pm 285^{\circ}$ & $444 \pm 356^{\bullet+}$ \\
\hline $\mathrm{Sv}, \mathrm{O}_{2} \%$ & $60 \pm 9$ & $66 \pm 7^{\circ}$ & $59 \pm 9$ & $66 \pm 7^{\circ}$ & $65 \pm 8^{\circ}$ \\
\hline Viral load $\log _{10} \cdot \mathrm{mm}^{-3}$ & $2.2 \pm 2.3$ & $2.0 \pm 2.1$ & $2.3 \pm 2.4$ & $2.0 \pm 1.9$ & $1.2 \pm 1.5^{\circ+}$ \\
\hline $\mathrm{CD}^{+}$cell count cells $\cdot \mathrm{mm}^{-3}$ & $379 \pm 296$ & $422 \pm 301$ & $391 \pm 316$ & $399 \pm 291$ & $454 \pm 311^{\circ+}$ \\
\hline
\end{tabular}

Data are presented as mean \pm SD, unless otherwise stated. WHO: World Health Organization; FC: functional class; $\bar{P}_{\text {ra: }}$ mean right atrial pressure; $\bar{P}_{\text {pa: }}$ mean pulmonary artery pressure; PVR: pulmonary vascular resistance; $\mathrm{Sv}_{\mathrm{O}_{2}}$ : mixed venous oxygen saturation. ${ }^{*}$ : last evaluation performed $29 \pm 15$ months after bosentan initiation (range 12-67 months); ${ }^{\circ}: p<0.005$ versus baseline; ${ }^{+}: p<0.05$ versus 4 -month evaluation.

patients were still receiving HAART, 29 (52\%) patients had undetectable viral load and $45(80 \%)$ had a CD4 $4^{+}$count $>200$ cells $\cdot \mathrm{mm}^{-3}$. At the last evaluation, $36(95 \%)$ out of 38 patients were receiving HAART, 21 (55\%) patients had undetectable viral load and $22(81 \%)$ had a $\mathrm{CD}^{+}$count $>200$ cells $\cdot \mathrm{mm}^{-3}$. None of the patients developed opportunistic infection during follow-up.

\section{Effects of bosentan therapy on overall and event-free survival}

At the cut-off date (December 1, 2007), the mean follow-up was $29 \pm 18$ months (range 1-64 months). A total of 44 patients were alive, including 36 receiving bosentan monotherapy and five receiving bosentan in combination with epoprostenol $(n=1)$, iloprost $(n=1)$ or sildenafil $(n=3)$. The three patients for whom bosentan treatment was withdrawn following elevation of liver enzymes were still alive and were not receiving any specific $\mathrm{PAH}$ therapy. These three patients did not receive sildenafil because of a potential drug-drug interaction as they were receiving protease inhibitors at the time. In addition, these three patients did not receive i.v. epoprostenol because they did not reach the criteria for i.v. therapy. Overall survival rates were $93 \pm 3,86 \pm 5$ and $66 \pm 8 \%$ at 1,2 and 3 yrs, respectively (fig. 1). Most of the 15 deaths were not related to PAH. The causes of death were sepsis $(n=6)$, complications of HIV infection (HIVassociated dementia; $n=1$ ), gastrointestinal bleeding related to portal hypertension $(n=2)$ or unknown cause $(n=2)$. Four patients died as a result of right heart failure. One patient died during combination therapy with epoprostenol and bosentan; the remaining 14 patients died while receiving bosentan monotherapy. The rates of event-free survival were $82 \pm 5 \%$, $73 \pm 6 \%$ and $54 \pm 8 \%$ at 1,2 , and 3 yrs, respectively (fig. 2).

The results of univariate analysis of the relationship between overall survival and variables measured at baseline are shown in table 4. History of right heart failure and baseline WHO FC IV were significantly related to overall survival. Co-infection with hepatitis B or C virus did not influence long-term survival. Similarly, the presence of mild cirrhosis did not affect outcomes.

\section{DISCUSSION}

The present study investigated a large number of consecutively enrolled patients with PAH-HIV treated with first-line bosentan. It confirms the short-term clinical and haemodynamic improvements observed in a previous 16-week pilot study [17]. In addition, the observed short-term improvements were sustained long-term in the majority of patients, resulting in favourable survival estimates. Moreover, long-term treatment with bosentan combined with HAART was well tolerated and was not associated with adverse effects or impaired control of HIV infection.

The mean treatment duration of 29 months enables an adequate evaluation of the potential long-term benefits of bosentan therapy in these patients to be made. The survival rates of 93,86 and $66 \%$ at 1,2 and 3 yrs, respectively, are better than those observed in a previous series of patients with $\mathrm{PAH}-$ HIV [5, 6]. PetitPRetz et al. [6] described a 2-yr survival of $46 \%$ in 20 PAH-HIV patients receiving supportive therapy alone. In a group of 82 patients receiving supportive therapy either alone $(n=62)$ or in combination with epoprostenol $(n=20)$, NuNES et al. [5] reported overall survival rates of 73, 60 and $47 \%$ at 1, 2 and 3 yrs, respectively. Using univariate analysis, the present authors found that patients in WHO FC IV at baseline and patients with a history of heart failure had an increased risk of mortality. This highlights the importance of screening patients with HIV infection and unexplained dyspnoea in order to start PAH-specific therapy early in the course of the disease before the occurrence of right heart failure [2]. In contrast with the study by NUNES et al. [5] where 75\% of deaths were related to pulmonary hypertension, the present authors found that most deaths in our population were related to infectious complication or bleeding in the context of portal hypertension [5, 6]. On multivariate analysis, NUNES et al. [5] identified that the $\mathrm{CD} 4^{+}$lymphocyte count was an independent predictor of better survival. In the current study, univariate analyses indicate that patients treated with HAART and patients with undetectable HIV viral load tend to have a better 


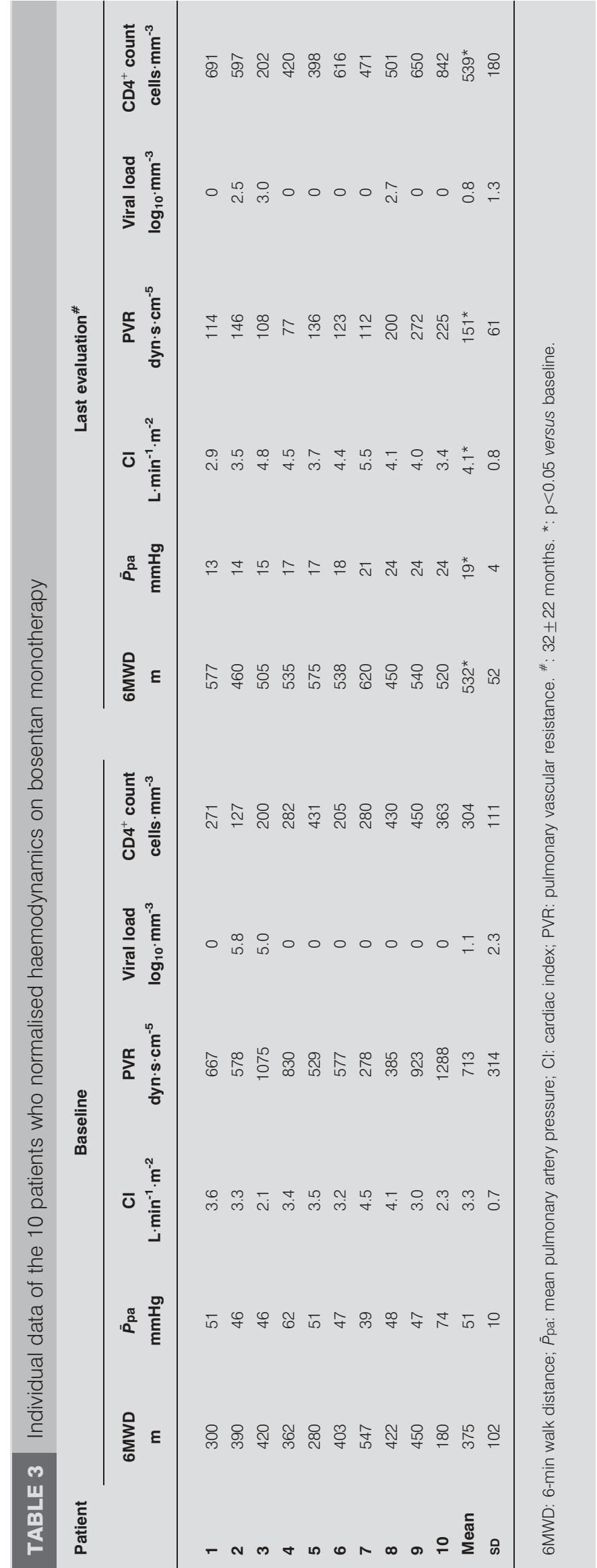

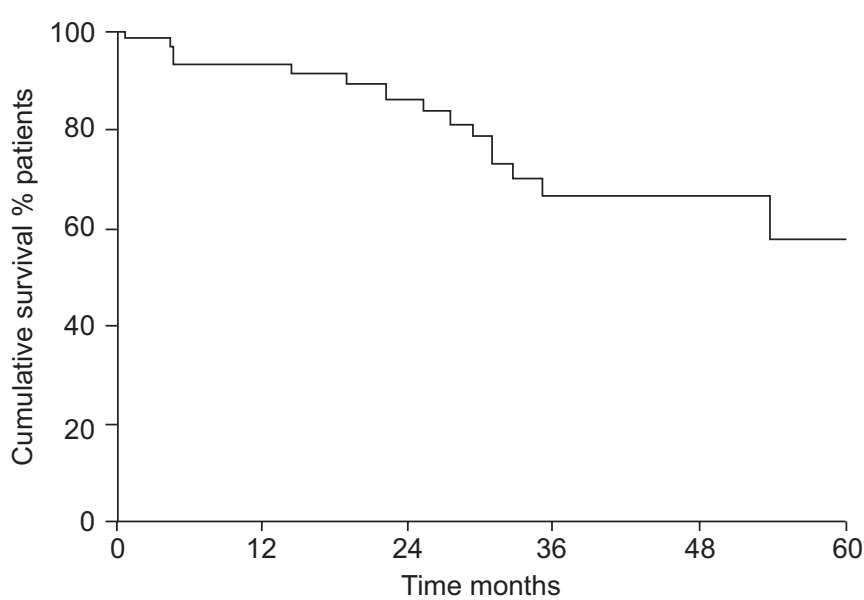

FIGURE 1. Kaplan-Meier estimates of survival in 59 patients with pulmonary arterial hypertension associated with HIV infection treated with first-line bosentan therapy. At 0,12, 24, 36, 48 and 60 months of treatment, the numbers of subjects at risk were $59,49,34,18,11$ and 2 , respectively.

prognosis. Haemodynamic parameters were not identified as predictors of survival, perhaps indicating that the beneficial effect of bosentan on haemodynamic parameters may have considerably changed the natural history of PAH-HIV.

Of considerable interest is the normalisation of haemodynamic parameters in 10 of the 59 patients who received bosentan monotherapy. This was not considered to result from less severe disease, as patients with or without normalised haemodynamics had similar functional and haemodynamic parameters and comparable HIV status at baseline. This finding is somewhat surprising because complete normalisation of haemodynamic parameters is exceptional with PAHspecific therapy (i.e. prostanoids and/or endothelin receptor antagonist and/or PDE5i) in patients with either IPAH or PAH associated with concomitant disease [19]. Some patients with $\mathrm{PAH}$ associated with some inflammatory diseases, such as

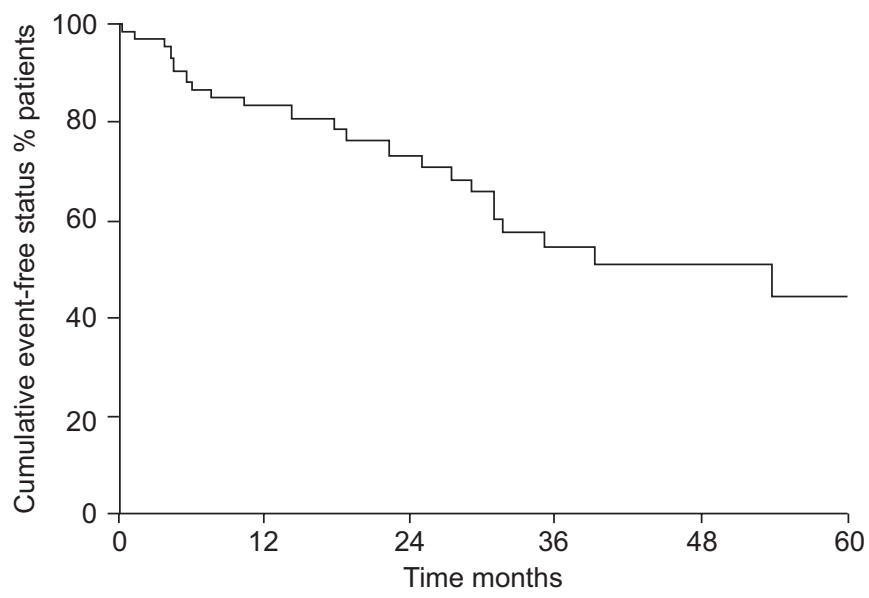

FIGURE 2. Kaplan-Meier estimates of event-free status in 59 patients with pulmonary arterial hypertension associated with HIV infection treated with first-line bosentan therapy. At $0,12,24,36,48$ and 60 months of treatment, the numbers of subjects at risk were $59,43,28,17,10$ and 2 , respectively. 


\begin{tabular}{|c|c|c|c|}
\hline \multirow{2}{*}{$\begin{array}{l}\text { TABLE } 4 \\
\text { Variable }\end{array}$} & \multicolumn{3}{|c|}{$\begin{array}{l}\text { Result of Cox regression analysis relating } \\
\text { prognostic factors for mortality to individual } \\
\text { selected variables at baseline }\end{array}$} \\
\hline & & $\begin{array}{c}\text { Hazard ratio } \\
(95 \% \mathrm{Cl})^{\#}\end{array}$ & p-value \\
\hline \multicolumn{2}{|l|}{ Female/male } & $0.51(0.14-1.84)$ & 0.32 \\
\hline \multicolumn{2}{|c|}{ History of right heart failure yes/no } & $3.11(1.12-8.62)$ & 0.03 \\
\hline \multicolumn{2}{|c|}{ Co-infection with $\mathrm{HBV}$ or HCV yes/no } & $0.85(0.30-2.39)$ & 0.76 \\
\hline \multicolumn{2}{|c|}{ Portal hypertension yes/no } & $0.30(0.04-2.32)$ & 0.25 \\
\hline \multicolumn{2}{|c|}{ WHO FC IV/III } & $4.58(1.41-14.85)$ & 0.02 \\
\hline \multicolumn{2}{|c|}{$6 M W D<368 \mathrm{~m}$ yes/no } & $1.00(0.34-2.91)$ & 0.90 \\
\hline \multicolumn{2}{|c|}{ Undetectable viral load yes/no } & $0.25(0.06-1.13)$ & 0.07 \\
\hline \multicolumn{2}{|c|}{$\mathrm{CD4}^{+}$lymphocyte count $>282$} & $0.49(0.17-1.37)$ & 0.17 \\
\hline \multicolumn{2}{|c|}{ HAART yes/no } & $0.32(0.10-1.03)$ & 0.06 \\
\hline \multicolumn{2}{|c|}{$\bar{P}_{\mathrm{ra}}>\mathbf{6} \mathbf{m m H g}$ yes/no } & $1.69(0.53-5.26)$ & 0.37 \\
\hline \multicolumn{2}{|c|}{$\bar{P}_{\mathrm{pa}}>\mathbf{4 7} \mathrm{mmHg}$ yes/no } & $0.79(0.28-2.17)$ & 0.64 \\
\hline \multicolumn{2}{|c|}{ Cardiac index $<2.93 \mathrm{~L} \cdot \mathrm{min}^{-1} \cdot \mathrm{m}^{-2}$ yes $/ \mathrm{no}$} & $3.24(0.91-11.52)$ & 0.07 \\
\hline \multicolumn{2}{|c|}{ PVR $>702$ dyn $\cdot \mathrm{s} \cdot \mathrm{cm}^{-5}$ yes $/$ no } & $1.85(0.62-5.26)$ & 0.27 \\
\hline \multicolumn{4}{|c|}{$\begin{array}{l}\text { Cl: confidence interval; HBV: hepatitis B virus; HCV: hepatitis C virus; WHO: } \\
\text { World Health Organization; FC: functional class; } 6 \mathrm{MWD} \text { : } 6 \text {-min walk distance; } \\
\text { HAART: highly active antiretroviral therapy; } \bar{P} \text { ra: mean right atrial pressure; } \bar{P} \text { pa: } \\
\text { mean pulmonary artery pressure; PVR: pulmonary vascular resistance. } \\
\# \text { : values of hazard ratio }>1 \text { indicate an increased risk of death. }\end{array}$} \\
\hline
\end{tabular}

systemic lupus erythematosus or mixed connective tissue disease, may achieve normalised haemodynamics with corticosteroids and/or immunosuppressive therapy. Recently, MONTANI et al. [24] reported a case of sustained normalisation in haemodynamics in a patient with comorbid HIV infection, human herpes virus 8 infection and Castleman's disease 5 yrs after a 12-month treatment combining cyclophosphamide, corticosteroids, HAART and epoprostenol [24]. In the current study, bosentan was withdrawn in a single patient who had a sustained 2-yr normalisation of haemodynamics while on bosentan. This patient remained stable 6 months after bosentan withdrawal.

While the pathogenesis and exact mechanism of development of PAH in patients with HIV have not been clearly defined, the benefits of bosentan suggest a key role of endothelin in this process. HIV is likely to play a role in the pathogenesis of PAH through the release of mediators associated with retroviral infection, namely platelet-derived growth factor and endothelin-1 [25]. HIV viral antigens are present in pulmonary endothelium and may directly stimulate abnormal apoptosis, growth and proliferation. Thus, glycoprotein 120, a viral protein necessary for the binding and entry of HIV into macrophages, has been shown to target human lung endothelial cells, increase markers of apoptosis and stimulate the secretion of endothelin-1 [26]. It has been shown that the membrane-trafficking regulator Nef increases apoptosis followed by proliferation of endothelial cells in vitro [27]. Finally, the HIV transcriptional transactivator protein has been shown to stimulate endothelial cell proliferation, resulting in the release of growth factors [27].
The management of PAH in HIV-infected patients is particularly challenging given the complexity and frequent changes of antiretroviral drug regimens. As a consequence, it is difficult to know whether a theoretical drug-drug interaction between bosentan and antiretroviral drugs may have had clinically relevant consequences in the current study population, and the current study was not designed to address this question. Despite this, the number of patients who were receiving HAART who had undetectable viral loads and whose $\mathrm{CD}^{+}$lymphocyte counts were $<200$ cells $\cdot \mathrm{mm}^{-3}$ is comparable to overall national data [28] and did not change with bosentan treatment.

Only three patients in the present study withdrew from bosentan treatment due to elevations of liver enzymes. Such elevations are a class effect of endothelin receptor antagonists. In a recent large-scale post-marketing surveillance, the frequency of liver enzyme elevations was no higher in HIVinfected patients than in patients with $\mathrm{PAH}$ due to other aetiologies [29].

The major limitation of the present study is its retrospective nature. Moreover, long-term functional and haemodynamic data on the effect of bosentan in the present patient population may have introduced selection bias since the analysis may have concentrated only on survivors or on patients who did not experience clinical deterioration and thus remained on monotherapy. Nevertheless, bosentan appeared to be at least as effective for treatment of PAH in HIV-infected patients as previously observed in double-blind, placebo-controlled studies in patients with IPAH and associated PAH [30] as well as the long-term open-label extensions of these studies [31]. Moreover, there are currently ethical reasons for not performing a controlled study of specific $\mathrm{PAH}$ therapies against placebo in patients with PAH-HIV given their poor prognosis with supportive therapies alone (e.g. anticoagulants, diuretics, oxygen) [5, 6]. Nevertheless, the availability of HAART has significantly improved the prognosis and quality of life of people living with HIV.

In summary, the current study indicates that the endothelin receptor antagonist bosentan provides long-term clinical and haemodynamic improvements, as well as a possible favourable impact on survival in HIV-infected patients with pulmonary arterial hypertension. Bosentan was observed to be safe in conjunction with highly-active antiretroviral therapy with no adverse effects on the control of HIV infection. The oral route of administration of bosentan is advantageous by comparison with that of parenteral prostanoids.

\section{REFERENCES}

1 Opravil M, Pechère M, Speich $\mathrm{R}$, et al. HIV-associated primary pulmonary hypertension. A case control study. Swiss HIV Cohort Study. Am J Respir Crit Care Med 1997; 155: 990-995.

2 Sitbon O, Lascoux-Combe C, Delfraissy JF, et al. Prevalence of HIV-related pulmonary arterial hypertension in the current antiretroviral therapy era. Am J Respir Crit Care Med 2008; 177: 108-113.

3 Humbert M, Sitbon O, Chaouat A, et al. Pulmonary arterial hypertension in France: results from a national registry. Am J Respir Crit Care Med 2006; 173: 1023-1030. 
4 Mehta NJ, Khan IA, Mehta RN, Sepkowitz DA. HIVrelated pulmonary hypertension: analytic review of 131 cases. Chest 2000; 118: 1133-1141.

5 Nunes H, Humbert M, Sitbon O, et al. Prognostic factors for survival in human immunodeficiency virus-associated pulmonary arterial hypertension. Am J Respir Crit Care Med 2003; 167: 1433-1439.

6 Petitpretz P, Brenot F, Azarian R, et al. Pulmonary hypertension in patients with human immunodeficiency virus infection. Comparison with primary pulmonary hypertension. Circulation 1994; 89: 2722-2727.

7 Galiè N, Torbicki A, Barst R, et al. Guidelines on diagnosis and treatment of pulmonary arterial hypertension. The Task Force on Diagnosis and Treatment of Pulmonary Arterial Hypertension of the European Society of Cardiology. Eur Heart J 2004; 25: 2243-2278.

8 Pellicelli AM, Palmieri F, Cicalini S, Petrosillo N. Pathogenesis of HIV-related pulmonary hypertension. Ann N Y Acad Sci 2001; 946: 82-94.

9 Zuber JP, Calmy A, Evison JM, et al. Pulmonary arterial hypertension related to HIV infection: improved hemodynamics and survival associated with antiretroviral therapy. Clin Infect Dis 2004; 38: 1178-1185.

10 Sitbon O, Humbert M, Jaïs X, et al. Acute vasodilator responsiveness and long-term response to calcium-channel blockers in different forms of pulmonary arterial hypertension. Am J Respir Crit Care Med 2004; 169: A210.

11 Aguilar RV, Farber HW. Epoprostenol (prostacyclin) therapy in HIV-associated pulmonary hypertension. Am J Respir Crit Care Med 2000; 162: 1846-1850.

12 Ghofrani HA, Friese G, Discher T, et al. Inhaled iloprost is a potent acute pulmonary vasodilator in HIV-related severe pulmonary hypertension. Eur Respir J 2004; 23: 321-326.

13 Alp S, Schlottmann R, Bauer TT, Schmidt WE, Bastian A. Long-time survival with HIV-related pulmonary arterial hypertension: a case report. AIDS 2003; 17: 1714-1715.

14 Wong AR, Rasool AH, Abidin NZ, Noor AR, Quah BS. Sildenafil as treatment for human immunodeficiency virus-related pulmonary hypertension in a child. J Paediatr Child Health 2006; 42: 147-148.

15 Highleyman L. Protease inhibitors and sildenafil (Viagra) should not be combined. BETA 1999; 12: 3.

16 Price LC, Howard LS. Endothelin receptor antagonists for pulmonary arterial hypertension: rationale and place in therapy. Am J Cardiovasc Drugs 2008; 8: 171-185.

17 Sitbon O, Gressin V, Speich R, et al. Bosentan for the treatment of human immunodeficiency virus-associated pulmonary arterial hypertension. Am J Respir Crit Care Med 2004; 170: 1212-1217.

18 Sitbon O, Humbert M, Jaïs X, et al. Long-term calciumchannel blockers in idiopathic pulmonary arterial hypertension. Circulation 2005; 111: 3105-3111.

19 Humbert M, Sitbon O, Simonneau G. Treatment of pulmonary arterial hypertension. N Engl J Med 2004; 351: 1425-1436.
20 Sterne JA, Hernán MA, Ledergerber B, et al. Long-term effectiveness of potent antiretroviral therapy in preventing AIDS and death: a prospective cohort study. Lancet 2005; 366: 378-384.

21 Cohen H, Chahine C, Hui A, Mukherji R. Bosentan therapy for pulmonary arterial hypertension. Am J Health Syst Pharm 2004; 61: 1107-1119.

22 American Thoracic Society Committee on Proficiency Standards for Clinical Pulmonary Function Laboratories. ATS statement: guidelines for the six-minute walk test. Am J Respir Crit Care Med 2002; 166: 111-117.

23 Provencher S, Sitbon O, Humbert M, Cabrol S, Jaïs X, Simonneau $G$. Long-term outcome with first-line bosentan therapy in idiopathic pulmonary arterial hypertension. Eur Heart J 2006; 27: 589-595.

24 Montani D, Achouh L, Marcelin AG, et al. Reversibility of pulmonary arterial hypertension in HIV/HHV8associated Castleman's disease. Eur Respir J 2005; 26: 969-972.

25 Humbert M, Monti G, Fartoukh M, et al. Platelet-derived growth factor expression in primary pulmonary hypertension: comparison of HIV seropositive and HIV seronegative patients. Eur Respir J 1998; 11: 554-559.

26 Ehrenreich H, Rieckmann P, Sinowatz F, et al. Potent stimulation of monocytic endothelin-1 production by HIV-1 glycoprotein 120. J Immunol 1993; 150: 4601-4609.

27 Barnett CF, Hsue PY, Machado RF. Pulmonary hypertension: an increasingly recognized complication of hereditary hemolytic anemias and HIV infection. JAMA 2008; 299: 324-331.

28 Delfraissy JF. République Française Ministère de la Santé et de la Protection Sociale. Prise en charge thérapeutique des personnes infectées par le VIH. Recommandations du groupe d'experts. Rapport 2004 sous la direction du Professeur JF Delfraissy, Ministère de la Santé et de la Protection Sociale. [Republic of France Ministry of Health and Social Protection. Therapeutic management of people infected with HIV. Recommendations of an expert group. 2004 report under the direction of Professor JF Delfraissy, Ministry of Health and Social Protection.] Paris, Médecines Sciences Flammarion, 2004. http:/ / lesrapports. ladocumentationfrancaise.fr/BRP/044000467/0000.pdf

29 Humbert M, Segal ES, Kiely DG, Carlsen J, Schwierin B, Hoeper MM. Results of European post-marketing surveillance of bosentan in pulmonary hypertension. Eur Respir J 2007; 30: 338-344.

30 Rubin LJ, Badesch DB, Barst RJ, et al. Bosentan therapy for pulmonary arterial hypertension. N Engl J Med 2002; 346: 896-903.

31 Sitbon O, McLaughlin VV, Badesch DB, et al. Survival in patients with class III idiopathic pulmonary arterial hypertension treated with first line oral bosentan compared with an historical cohort of patients started on intravenous epoprostenol. Thorax 2005; 60: 1025-1030. 